\title{
PROPRIEDADES DA SEDA DE ARANHA NO RAMO MEDICINAL: UMA REVISÃO DE LITERATURA
}

\author{
Irineu Ferreira da Silva Neto ${ }^{1}$, Ana Emília Formiga Marques ${ }^{2}$ \\ ${ }^{1}$ Curso de Bacharelado em Farmácia, Unidade Acadêmica de Saúde, Faculdade de Medicina \\ Estácio de Juazeiro do Norte, Juazeiro do Norte-CE, Brasil. \\ ${ }^{2}$ Prof ${ }^{a}$ Unidade Acadêmica de Saúde, Faculdade de Medicina Estácio de Juazeiro do Norte, \\ Juazeiro do Norte-CE, Brasil. \\ Email para correspondência: yrineuferreira@gmail.com
}

\begin{abstract}
Resumo
Desde a antiguidade a seda de aranha vem sendo utilizada com a finalidade medicinal, suas características lhe proporcionam ser uma alternativa terapêutica diante de diferentes abordagens. Objetivou-se revisar por meio da literatura as propriedades e peculiaridades da seda de aranha no ramo medicinal, e também discutir algumas de suas variadas aplicações. Revisão de literatura nas bases de dados eletrônicas: LILACS, SCIELO, PubMed e CAPES de publicações entre 2007 e 2020, utilizando como descritores: "Fibroínas de Aranha", "Biomaterial" e "Biotecnologia". Os critérios de inclusão foram: publicações em português ou inglês, que se tratassem de estudos experimentais, descritivos ou exploratórios dentro do período estabelecido, contendo pelo menos um dos descritores. Os estudos mostram as propriedades e capacidades cicatrizantes, antimicrobiana, alta elasticidade, podendo auxiliar em procedimentos dermatológicos e assumir diferentes papéis em aplicações cirúrgicas. No ramo de cosméticos, aumenta o brilho e suavidade dos produtos, além disso, possui outras aplicações. Há uma vasta aplicabilidade do uso da teia de aranha no ramo da medicina, devido suas capacidades mecânicas e aspectos físico-químicos. Estudos devem prosseguir a afim de avaliar qualitativamente e quantitativamente o teor de proteínas funcionais, e possivelmente outras aplicações.
\end{abstract}

Palavras-chave: Biomaterial, biotecnologia, Fibroínas de aranha.

\begin{abstract}
Since ancient times spider silk has been used for medicinal purposes, its characteristics are provided as a therapeutic alternative in the face of different approaches. Objective-to review through the literature as properties and peculiarities of spider silk in the medicinal branch, and also to discuss some of its varied applications. Literature review in the electronic databases: LILACS, SCIELO, PubMed and CAPES of publications between 2007 and 2020, using as descriptors: "Spider Fibroins", "Biomaterial" and "Biotechnology". The inclusion criteria were: publications in Portuguese or English, which deal with experimental, descriptive or exploratory studies within the established period, including less than one descriptor. Studies show how properties and scars, antimicrobial, high elasticity, can assist in dermatological procedures and perform different
\end{abstract}


applications in surgical applications. No cosmetics branch, it increases the brightness and softens the products, besides, it has other applications. There is a wide application of the use of spiders in the field of medicine, due to its mechanics and physical-chemical aspects. Studies should follow to assess qualitatively and quantitatively or the content of functional proteins, and other possible applications.

Keywords: Biomaterial, Biotechnology, Spider fibroins.

\section{Introdução}

O uso de insetos no ramo medicinal é algo ainda motivo de estranhamento no meio científico, no qual se dá por ser uma prática bastante diferenciada, mas muito recorrente nos séculos anteriores, visando amenizar as enfermidades. Eram recorrentemente empregados pelos indígenas, fazendo parte de suas práticas curativas. Por ter o uso terapêutico bastante complexo, usualmente são desenvolvidas pesquisas que ajudam a desvendar as diversas propriedades (JOAQUIM, 2014).

Existe um vasto conhecimento popular acerca da arcnofauna com a finalidade de tratar afecções popularmente conhecidas (SOUZA, 2007). Acreditava-se que as aranhas possuíam propriedades que possibilitavam amenizar a febre, e para isso deveriam apenas amassá-las e pendurá-las no pescoço. Já os fios de sedas (teias) acreditavam-se que possuíam ação adstringente, além de serem tradicionalmente empregados para diminuir sangramentos em feridas, auxiliar na cicatrização e inflamação, porém, ainda não havia comprovações da sua real efetividade (JOAQUIM, 2014).

As aranhas são aracnídeas, pertencentes ao filo Arthropoda, e ordem Araneae, ocupam o sétimo lugar na diversidade total de espécies dentre todos os grupos de organismos. Possuem fiandeiras, de dois a quatro pares, essas são estruturas exclusivas e responsáveis por conter as glândulas produtoras de seda. Podem frequentemente habitar diversificados espaços e ecossistemas, moldando suas teias geométricas ou irregulares. As sedas produzidas pelas aranhas são secretadas por glândulas abdominais especializadas, estas possuem apêndices modificados que diferem na arquitetura funcional de acordo com o gênero e espécie. Formam-se os biopolímeros por meio de uma série de fiandeiras, podendo estar localizadas em três regiões: porção caudal, porção mediana dilatada secretora e na extremidade do abdômem (ESTEVES, 2017). 
Já foi possível identificar cinco tipos de sedas, que são: Ampola da principal, Ampola da secundária, Tubuliforme, Aciniforme e Espiral de captura. São 39.725 espécies de aranhas capazes de produzir a seda, sendo que a arquitetura molecular mostra a possibilidade de formação das proteínas MaSp1, MaSp2, MiSp1, MiSp2 e Flag, cada uma com características e morfologias diferenciadas. Assim, com os avanços na engenharia genética, abriu-se a possibilidade de produzir sedas recombiantes com propriedades controladas para aplicações biotecnológicas (BITTENCOURT, 2016).

Os fios de seda produzido pelas aranhas são constituídos por uma variedade de filamentos proteicos, e seu papel é essencial nas capturas de suas presas e construção de ootecas. Esses diversificados filamentos podem ser provenientes de cinco tipos de glândulas saricígenas, encontradas na região abdominal. Cada filamento oriundo possui propriedades e composição de aminoácidos distintas, dependendo de onde foi excretado. Os aminoácidos são envoltos por uma película aquosa que auxilia nas suas propriedades antimicrobianas, e isso impede enfraquecimento da teia. Contém ademais, enxofre, glicoproteínas, sais inorgânicos e outros componentes químicos que também são de suma importância para o controle microbiano (ZORTÉA; FISCHER, 2009). As principais proteínas presentes na seda da aranha são: glicina, alanina e prolina, constituindo uma rede sequencial com propriedades de difícil caracterização (LACERDA, 2015).

A seda de aranha vem sendo alvo de pesquisas nas ciências dos materiais, estas, buscam suas características físicas, químicas e estruturais, afim de consolidar os dados sobre sua composição e possivelmente induzir aplicações (TSUNEDA et al., 2015). Possui propriedades notáveis, destacandose: elasticidade, resistência mecânica, degradabilidade mínima, além de biocompatibilidade (NETO, 2020).

Os biomateriais das aranhas ganham visibilidade, pois ao entrarem em contato com tecidos vivos não desencadeiam resposta alérgica ou inflamatória. Existe a possibilidade de seu uso em redes otimizadas de fibras em processos biológicos, físicos e químicos, como: catálise química, reações enzimáticas e propagação elétrica de sinais (MENEZES, 2010). 
Diante dos dados expostos, esse estudo objetiva revisar por meio da literatura as propriedades e peculiaridades da seda de aranha no ramo medicinal, e também discutir algumas de suas variadas aplicações.

\section{Metodologia}

Foi realizada uma revisão de literatura nas base de dados eletrônicas: LILACS (Literatura Latino-americana e do Caribe em Ciências da Saúde), SCIELO (Scientific Electronic Library Online), PubMed (National Library of Medicine) e CAPES (Portal Periódicos), de estudos nos idiomas inglês ou português, utilizando como descritores: "Fibroínas de Aranha", "Biomaterial" e "Biotecnologia".

Os critérios de inclusão foram: estudos em inglês ou português, publicados de 2007 a 2020, conforme a tabela 1, e que se tratassem de estudos experimentais, descritivos ou exploratórios. Estudos em outras línguas, fora do período escolhido, incompletos ou que não abordavam sobre o tema foram excluídos.

A pesquisa literária possibilitou encontrar nas bases de dados 841 artigos que abordavam sobre a temática, mas apenas 9 desses artigos continham informações de relevância perante a abordagem exposta. Foi levado em consideração dados qualitativos encontrados na produção científica mundial para síntese do estudo.

\section{$3 \quad$ Resultados e discussões}

Algumas aplicações do biomaterial da seda de aranha já foram estudadas pelos pesquisadores, dentre elas: antimicrobiana, na regeneração de tecidos, recobrimento de superfícies funcionais e outras, assim os estudos de maior relevância encontrados na literatura podem ser visualizados na Tabela 1. 
Tabela 1. Caracterização da produção científica.

\begin{tabular}{|c|c|c|c|}
\hline Autor/ano & Objetivo & Metodologia & Resultados \\
\hline $\begin{array}{c}\text { Zortéa; } \\
\text { Fischer, } \\
2009\end{array}$ & $\begin{array}{l}\text { Verificar a atividade } \\
\text { antimicrobiana nos } \\
\text { constituintes da } \\
\text { teia. }\end{array}$ & $\begin{array}{l}\text { Técnicas de } \\
\text { difusão de poços } \\
\text { e difusão de } \\
\text { disco. }\end{array}$ & $\begin{array}{l}\text { A barreira física } \\
\text { parece ter maior } \\
\text { importância contra o } \\
\text { crescimento de } \\
\text { microrganismos do } \\
\text { que a química e } \\
\text { mostra eficiência } \\
\text { antibacteriana. }\end{array}$ \\
\hline $\begin{array}{l}\text { Souto et al., } \\
2007\end{array}$ & $\begin{array}{l}\text { Identificar quatro } \\
\text { proteínas } \\
\text { produzidas pelas } \\
\text { glândulas } \\
\text { ampoladas (maior e } \\
\text { menor), } \\
\text { flageliforme } \\
\text { tubiliforme da } \\
\text { espécie de aranha } \\
\text { brasileira } \\
\text { Nephilengys } \\
\text { cruentata (Araneae: } \\
\text { Nephilidae). }\end{array}$ & \begin{tabular}{|lr} 
Utizando & \\
seqüências & \\
expressas & nas \\
glândulas & da \\
seda. & \\
\end{tabular} & $\begin{array}{lr}\text { As novas } & \text { proteínas } \\
\text { ídentificadas } & \\
\text { mostraram } & \text { grande } \\
\text { similaridade } & \text { com } \\
\text { outras } & \text { sedas } \\
\text { previamente } & \\
\text { descritas. } & \text { Dentre } \\
\text { essas sedas, a } & \text { a } \\
\text { produzida } & \text { pela } \\
\text { glândula flageliforme } \\
\text { (NCFlag-like) } \\
\text { extremamente } \\
\text { elástica. }\end{array}$ \\
\hline $\begin{array}{c}\text { Weska et al., } \\
2009\end{array}$ & $\begin{array}{lr}\text { Estudar } & \text { a } \\
\text { possibilidade } & \text { de } \\
\text { aplicação } & \text { de } \\
\text { membranas } & \text { de } \\
\text { fibroína } & \text { como } \\
\text { biomaterial, } & \text { pelo } \\
\text { estudo } & \text { da } \\
\text { calcificação in vitro. }\end{array}$ & $\begin{array}{l}\text { Para os ensaios } \\
\text { de calcificação in } \\
\text { vitro, as } \\
\text { membranas de } \\
\text { fibroína foram } \\
\text { imersas em SBF } \\
\text { por sete dias, e } \\
\text { caracterizadas } \\
\text { por MEV e EDX. }\end{array}$ & $\begin{array}{l}\text { Os resultados obtidos } \\
\text { de calcificação in vitro } \\
\text { indicaram que a } \\
\text { fibroína pode induzir a } \\
\text { calcificação, pela } \\
\text { formaça } \\
\text { depósitos de fosfato } \\
\text { de cálcio com } \\
\text { relações de } \mathrm{Ca} / \mathrm{P} \\
\text { similares à da } \\
\text { hidroxiapatita e seus } \\
\text { precursores, podendo } \\
\text { ser considerada para } \\
\text { aplicação em } \\
\text { regeneração óssea. }\end{array}$ \\
\hline $\begin{array}{l}\text { Dos Santos } \\
\text { et al., } 2018\end{array}$ & $\begin{array}{lr}\text { Analisar } & \text { os } \\
\text { processos } & \text { de } \\
\text { gelificação } & \text { para } \\
\text { obtenção } & \text { de } \\
\text { membranas } & \\
\text { porosas de fibroína } \\
\text { e caracterizar } & \text { as } \\
\text { amostras. } & \end{array}$ & \begin{tabular}{lr}
\multicolumn{2}{|l}{ Foram realizadas } \\
mudanças nos \\
seguintes \\
parâmetros de \\
processamento: \\
tempo, \\
temperatura e \\
tipo & de \\
membrana & de \\
diálise. & \\
\end{tabular} & $\begin{array}{lr}\text { Dentre as } & \text { amostras } \\
\text { analisadas, } & \text { fo } \\
\text { observado que o } \\
\text { tempo de diálise } \\
\text { influenciam r na } \\
\text { formação do gel, para } \\
\text { a síntese de } \\
\text { membranas porosas e } \\
\text { aplicação r desses } \\
\text { biomateriais. }\end{array}$ \\
\hline & Explorar a fibroína & \begin{tabular}{|l} 
Foi estudada a \\
\end{tabular} & A fibroína de seda e \\
\hline
\end{tabular}




\begin{tabular}{|c|c|c|c|}
\hline $\begin{array}{c}\text { Moraes, } \\
2014\end{array}$ & $\begin{array}{l}\text { de seda no preparo } \\
\text { de materiais micro } \\
\text { e } \\
\text { nanoestruturados, } \\
\text { em estruturas bi e } \\
\text { tridimensionais } \\
\text { visando o uso em } \\
\text { biomateriais. }\end{array}$ & $\begin{array}{lr}\text { incorporação } & \text { de } \\
\text { microfibras } & \text { de } \\
\text { fibroína } & \text { em } \\
\text { hidrogéis } & \text { de } \\
\text { colágeno, } & \\
\text { formando uma } \\
\text { estrutura 3D, e a } \\
\text { formação de } \\
\text { filmes ultrafinos } \\
\text { contendo fibroína } \\
\text { pelo método } \\
\text { layer-by-layer. }\end{array}$ & $\begin{array}{l}\text { representam um } \\
\text { material promissor } \\
\text { para uso em } \\
\text { engenharia tecidual } \\
\text { vascular e ainda } \\
\text { possuem potencial na } \\
\text { área biomédica, como } \\
\text { recobrimentos e } \\
\text { superfícies funcionais. }\end{array}$ \\
\hline $\begin{array}{c}\text { Rodrigues et } \\
\text { al., } 2017\end{array}$ & \begin{tabular}{lr} 
Analisar & e \\
comparar & a \\
\multicolumn{2}{l}{ biodegradabilidade } \\
do Filme de \\
Fibroína, Hidrogel \\
de Alginato de \\
Sódio, Filme de \\
Acetato & de \\
Celulose e Filme de \\
Acetato r de \\
Celuloserram \\
Nanofibras.
\end{tabular} & $\begin{array}{lr}\text { Teste de Sturm } \\
\text { que avalia a } \\
\text { produção de } \mathrm{CO}_{2} \\
\text { durante r o } \\
\text { processo de } \\
\text { biodegradação } \\
\text { por meio da } \\
\text { ação } \quad \text { de } \\
\text { microrganismos } \\
\text { presentes no } \\
\text { solo. }\end{array}$ & $\begin{array}{l}\text { Os resultados } \\
\text { mostraram-se } \\
\text { positivos na perda de } \\
\text { massa e geração de } \\
\mathrm{CO}_{2} \text { e água, podendo } \\
\text { ser considerado } \\
\text { biodegradável em } \\
\text { outra norma, ou após } \\
\text { estudos mais } \\
\text { aprofundados destes } \\
\text { materiais }\end{array}$ \\
\hline $\begin{array}{c}\text { Menezes, } \\
2010\end{array}$ & $\begin{array}{l}\text { Avaliar as fibras } \\
\text { sintéticas } \\
\text { qualitativa } \\
\text { quantitativamente, } \\
\text { apontando MFA e } \\
\text { MEV para } \\
\text { descrever de forma } \\
\text { única os detalhes } \\
\text { particulares da } \\
\text { estrutura de } \\
\text { superfície das } \\
\text { fibras sintéticas de } \\
\text { aranha. }\end{array}$ & $\begin{array}{l}\text { Microscopia de } \\
\text { força atômica } \\
(\mathrm{MFA}) \\
\text { microscopia e } \\
\text { eletrônica de } \\
\text { varredura (MEV). }\end{array}$ & $\begin{array}{l}\text { A sequência primária } \\
\text { das proteínas é } \\
\text { fundamental para as } \\
\text { propriedades } \\
\text { mecânicas das fibras } \\
\text { que podem ser fontes } \\
\text { de estudos } \\
\text { posteriores em } \\
\text { diversas aplicações. }\end{array}$ \\
\hline $\begin{array}{c}\text { Tahir et al., } \\
2019\end{array}$ & $\begin{array}{l}\text { Explorar a potencial } \\
\text { aplicação de seda } \\
\text { de aranha como } \\
\text { um revestimento } \\
\text { conservante } \\
\text { inodoro. }\end{array}$ & $\begin{array}{lr}\text { A seda } & \text { foi } \\
\text { coletada } & \text { de } \\
\text { aranhas criadas } \\
\text { em laboratório, } \\
\text { seguindo-se a } \\
\text { degomagem } \\
\text { dissolução para } \\
\text { formular ra } \\
\text { solução de seda. }\end{array}$ & $\begin{array}{l}\text { Os frutos revestidos } \\
\text { de seda mostraram } \\
\text { menos perda de água } \\
\text { e foram protegidos } \\
\text { contrar ataques } \\
\text { fúngicos. Portanto, o } \\
\text { estudor fornece } \\
\text { evidências } \\
\text { convincentes sobre a } \\
\text { aplicação de seda de } \\
\text { aranha como um } \\
\text { revestimento. }\end{array}$ \\
\hline & Identificar o perfil & Abordagem & Os resultados obtidos \\
\hline
\end{tabular}




\begin{tabular}{|c|c|c|c|}
\hline Pinto, 2014 & $\begin{array}{l}\text { proteico das } \\
\text { glândulas que } \\
\text { secretam a seda da } \\
\text { aranha } N \text {. clavipes, } \\
\text { como também as } \\
\text { proteínas } \\
\text { constituintes dessa } \\
\text { seda com a } \\
\text { obtenção de uma } \\
\text { elevada cobertura } \\
\text { da sequência e } \\
\text { detecção de suas } \\
\text { PTMs. }\end{array}$ & $\begin{array}{l}\text { proteômica } \\
\text { bottom-up com a } \\
\text { utilização } \\
\text { combinação da 2- } \\
\text { DE, } \\
\text { cromatografia } \\
\text { líquida e } \\
\text { espectrometria } \\
\text { de massas } \\
\text { (NanoLC-ESI- } \\
\text { CID/ETD-MSn). }\end{array}$ & $\begin{array}{l}\text { para as espidroínas } \\
\text { poderá proporcionar } \\
\text { uma melhor } \\
\text { compreensão das } \\
\text { propriedades da seda } \\
\text { visando à produção } \\
\text { sintética/recombinante } \\
\text { de novos materiais à } \\
\text { base da seda de } \\
\text { aranhas. }\end{array}$ \\
\hline
\end{tabular}

Fonte: Dados da pesquisa, 2020.

Identifica-se na tabela 1 que dois artigos foram publicados nos anos de 2009 e 2014 e apenas um nos anos de 2007, 2010, 2017, 2018 e 2020, respectivamente. As pesquisas identificadas puderam avaliar as propriedades da seda de aranha em vários seguimentos, sendo que a maioria delas buscou indentificar novas proteínas ou caracteriza-las. Mas, ressalta-se que ainda existem poucos estudos nessa área, o que expõe a importância desse estudo, tanto para disseminar as suas funcionalidades, quanto para instigar 0 desenvolvimento de novas pesquisas.

As aplicações do biomaterial proveniente da seda de aranha vem sendo cada vez mais discutidas nas aplicações biomédicas devido a união de propriedades pertencentes, dentre elas: mecânicas, biocompatibilidade e reduzida biodegradabilidade. Esse biomaterial tem mostrado ser um futuro promissor para engenharia de tecidos esqueléticos, atuando como fios de suturas mais delgados e potentes para aplicações em substituição de ligamentos ou tendões. Em consonância, a biocompatibilidade mostra que um recombinante o rS1/9 scaffolds, sendo análogo da proteína espidroína 1 que está presente na teia de aranha, detém possivelmente condições para ser usado na regeneração de tecidos in vivo (PINTO, 2014). Por isso, esse biomaterial deve ser alvo de novas pesquisas com o intuito de se apropriar dessas funcionalidades.

Na prática medicinal, a teia de aranha se mostra oportuna, pois além de ser portadora de propriedades antimicrobianas, tem aspecto adstringente e pode auxiliar em procedimentos dermatológicos, nos tratamentos de lesões na 
pele, e devido sua grande resistência, é possível sua utilização em procedimentos cirúrgicos (ZORTÉA; FISCHER, 2009). E, atualmente tem se buscado substitutos funcionais devido a falhas em outros tratamentos para aplicação nesse seguimento, assim a utilização de análogos da seda poderiam minimizar o impacto negativo, como uma terapia alternativa aos substitutos convencionais (NETO, 2020).

As proteínas que fazem parte da composição da seda são totalmente solúveis em água, solventes orgânicos e líquidos iônicos, dessa forma, possibilita diversas opções para produção dos biomateriais nas aplicações biomédicas. Há possibilidade também de sua aplicação nos cosméticos, dentre eles: xampus, sabonetes e cremes, dando resistência aos produtos, salientando o brilho e suavidade (PINTO, 2014). Para melhor manejo de suas funcionalidades e aplicação em grande escala, é necessário buscar conhecer as principais proteínas funcionais, bem como buscar avaliar mais especificamente as aranhas que as produzem com maior frequência.

As diferentes sedas produzidas pelas aranhas contêm propriedades moleculares impressionantes. Experimentos realizados por Souto et al. (2007), possibilitaram isolar quatro tipos de proteínas da espécie Nephilengys Cruentata, dando destaque para a seda NCFlag-like, que é incrivelmente elástica e pode ser vista como um objeto de estudo, tanto para a produção de novos biomateriais, quanto possivelmente para o uso em procedimentos cirúrgicos. Mesmo estas sendo produtos oriundos da natureza, cabe salientar a importância de estudos in vivo que consigam mensurar o seu grau de aceitação nos diferentes tecidos, além avaliar seus efeitos a curto e longo prazo.

A propriedade antimicrobiana encontrada por meio do estudo de Zortéa e Fischer (2009), mostra que a seda impossibilita o desenvolvimento de bactérias ou fungos que pudessem contaminar e propiciar seu descolamento. Os fios que envolvem as presas são secretados pelas glândulas aciniformes, e diferem na composição dos demais, portanto, acredita-se que seja somente tais fios com propriedades antimicrobianas. As aranhas do gênero Loxosceles, as L. laeta e L. intermedia apesar de possuírem comportamentos ecológicos diferentes, ambas possuem atividade antimicrobiana. Ao avaliar essa propriedade das teias, as pesquisas mostram o aparecimento de fungos ou bactérias só foi 
constatado onde haviam ausência da seda. A teia é vista como uma barreira física que evita a proliferação de microrganismos.

Alguns produtos já estão sendo desenvolvidos a partir das proteínas contidas na seda da aranha, estes foram empregados com o intuito de proteger a pele, propiciando um equilíbrio na umidade, sendo um futuro promissor na indústria de cosméticos. Ainda não foi possível determinar a composição proteica de todos os tipos de sedas, mas, já sabe-se que essa composição é variada de acordo com a espécie que a produz, e a sequências de aminoácidos altamente diversificada (PINTO, 2014). Esses filamentos proteicos podem ser fontes promissoras nos diversos seguimentos.

A fibroína presente na seda possui aplicação funcional para ser utilizada como suporte para mimetizar a biomineralização, segundo o estudo de Weska et al. (2009), dessa forma, detém aproveitamento na calcificação e regeneração óssea. Isso se dá por meio da formação de fosfato de cálcio, induzidas pelas fibroínas, se assimilando a hidroxiapatita e seus precursores. Enquanto Dos Santos et al. (2018) expõem que as fibroínas em forma de filme podem incorporar moléculas para a sinalização de células lábeis, assim como ativos de liberação prolongada.

Diversos setores vêm buscando métodos alternativos por meio de polímeros biodegradáveis, pois estes são desenvolvidos com o intuito de se desfazer ao entrar em contato com o corpo, e posteriormente excretados naturalmente. As fibroínas são capazes de atender a tais quesitos, principalmente comparando a outros compostos (RODRIGUES et al., 2017).

O estudo de Moraes (2014) expõe que a biocompatibilidade entre a seda e as células mostram resultados promissores, de forma a haver considerável interação entre as fibroínas e as fibrilas de colágeno, além disso, há melhoramento da proliferação celular. $O$ mesmo estudo ainda supõe que a seda de aranha tem utilidade no recobrimento e superfícies funcionais. Enquanto o estudo de Tahir et al. (2019), ao fazerem avaliações para utilização da seda como revestimento conservante, mostrou-se promissor perante os experimentos realizados com frutos de damasco, de forma a reduzir a perda de água e evitar a proliferação de fungos. Esse experimento pôde expor sua 
versatilidade e funcionalidade antimicrobiana, além de instigar sua aplicação em outros seguimentos.

A grande dificuldade, segundo Menezes (2010), é a produção de sedas sintéticas com propriedades compatíveis as sedas naturais, em especial, características ultra estruturais, nano estruturais e mecânicas. Ademais, o processo de geração da seda ainda não é totalmente conhecido, sendo necessárias ainda mais informações genéticas, afim de elucidar a capacidade e propriedades das sedas naturais, tornando-se um desafio a ser vencido para sua maior aplicação.

Outra dificuldade encontrada para utilização da seda no ramo medicinal, e posteriormente em grande escala, é domesticação das aranhas, pois estas possuem comportamentos agressivos e territorialistas. Para minimizar esse impasse, estão sendo desenvolvidas materiais com propriedades semelhantes a partir da tecnologia do DNA recombinante (SILVA, 2014).

É notória que a seda de aranha contém características únicas para ser amplamente utilizada, e mostra-se ser um recurso alternativo para ser aplicado no ramo biotecnológico, devido suas diversas capacidades mecânicas e aspectos físico-químicos (PINTO, 2014).

\section{Conclusão}

A pesquisa pôde mostrar a grande utilidade da seda de aranha nos diversos seguimentos, visto que, suas propriedades são bastante peculiares, fazendo com que a biotecnologia e outras ciências busquem cada vez mais se aproximar, ou usufruir de forma viável os recursos que esse biomaterial tem a oferecer. Contudo, suas características Ihe proporcionam ser uma alternativa terapêutica diante de diferentes abordagens.

Assim, é necessário prosseguir com pesquisas nos setores tecnológicos afim de avaliar qualitativamente e quantitativamente 0 teor de proteínas funcionais. Ademais, comprovar sua real efetividade in vivo, e garantir que não possibilitem efeitos negativos a curto e longo prazo.

Além disso, desenvolver pesquisas que possibilitem a produção de análogos, já que há dificuldade para a produção de seda natural em grande escala. 


\section{Referências}

BITTENCOURT, Daniela Matias de Carvalho. Spider silks and their biotechnological applications. In: Short Views on Insect Genomics and Proteomics. Springer, Cham, 2016. p. 211-227.

DOS SANTOS, Wilma Tainá Pereira; CELESTINO, Juliana; ARANHA, Norberto. ESTUDO DE PROCESSO DE GELIFICAÇÃO DA FIBROÍNA NA FORMAÇÃO DE MEMBRANAS. In: Portal de eventos científicos da UNISO, Relatório Parcial IC 2017/2018. 2018.

ESTEVES, Franciele Grego. Caracterização proteometabolômica dos componentes da teia da aranha Nephila Chavipes utilizados na estratégia de captura de presas. 2017. 223f. Dissertação (Mestrado em Biologia Celular e Molecular) - Universidade Estadual Paulista, Instituto de Biociências de Rio Claro, 2017.

JOAQUIM, Mariana Alliatti. Bastaba esta general insinuación de la utilidad, que saca la Medicina de los Insectos, para apreciarlos [...]: um estudo das virtudes terapêuticas de insetos na obra Paraguay Natural, do padre jesuíta José Sanchez Labrador. Revista Latino-Americana de História, v. 3, n. 12, p. 70-84, 2014.

LACERDA, Valquíria Alice Michalczechen. Produção de proteínas MaSp da Aranha Parawixia bistriata por bactérias modificadas metabolicamente, e caracterização molecular das fibras sintéticas. 2015. $171 \mathrm{f}$. Tese (Doutorado em Biologia Molecular) - Universidade de Brasília, Brasília, 2015.

MENEZES, Gabriela Matsunaga. Investigações estruturais de fibras sintéticas de aranha produzidas por meio de expressão recombinante. 2010. 119 f., il. Dissertação (Mestrado em Biologia Molecular) - Universidade de Brasília, Brasília, 2010.

MORAES, Mariana Agostini. Obtenção e caracterização de materiais micro e nanoestruturados contendo fibroína de seda combinada a outros polímeros biocompatíveis para contato com células. 2014. 124 p. Tese (doutorado) Universidade Estadual de Campinas, Faculdade de Engenharia Química, Campinas, SP. 2014. 
NETO, Irineu Ferreira da Silva. Recombinante rS1 / 9 análogo da proteína spidroin 1 da seda de aranha Nephila Chavipes como projeção de biomaterial na regeneração tecidual. Revista de Bioctenologia \& Ciência. v. 9, n. 1, p. 18-24, 2020.

PINTO, José Roberto Aparecido dos Santos. Análise estrutural das proteínas da seda da teia da aranha Nephila clavipes por uma abordagem proteômica. 2014. 287 f. Tese - (doutorado) - Universidade Estadual Paulista, Instituto de Biociências de Rio Claro, 2014.

RODRIGUES, Aline Dayane. et al. ESTUDO COMPARATIVO DE BIODEGRADAÇÃO DE BIOPOLÍMEROS COM APLICAÇÕES FARMACÊUTICAS. In: 17ํㅡㄴ Congresso Nacional de Iniciação Científica. UNIVERSIDADE DE SOROCABA. 2017.

SILVA, Otávio Bravim. Expressão e purificação de proteína de glândula Sericígena da aranha Parawixia bistriata em bactérias geneticamente modificadas. 2014. xv, 83 f., il. Dissertação (Mestrado em Biologia Molecular) — Universidade de Brasília, Brasília, 2014.

SOUTO, Betúlia de Morais. et al. Produção e purificação de seda recombinante da aranha brasileira Nephilengys cruentata. In: CONGRESSO BRASILEIRO DE GENÉTICA, 53., 2007, Águas de Lindóia. Anais... Águas de Lindóia: SBG, 2007., 2007.

SOUZA, José Hélio de. Os aracnídeos (Arachnida: Araneae, Scorpiones) na comunidade quilombola de Mesquita, Goiás: um estudo de caso sobre etnobiologia. 2007. 114 f. Dissertação (Mestrado em Biologia Animal) -Universidade de Brasília, Brasília, 2007.

TAHIR, Hafiz Muhammad et al. Coating of spider silk enhanced the preservation and shelf life of apricot. Braz. J. Biol., São Carlos, v. 80, n. 1, p. 115-121, Feb. 2019.

TSUNEDA, Simone Sayuri; FIGUEIREDO, Luciana Harumi Morimoto; LEOPOLDO, Elíbio Leopoldo. MONITORAMENTO TECNOLÓGICO RELACIONADO A GENES E PROTEÍNAS DA TEIA DE ARANHAS NO INCREMENTO ESTRUTURAL DE MATERIAIS. Cadernos de Prospecção, v. 8, n. 4, p. 713, 2015. 
WESKA, Raquel Farias et al. Estudo da esterilização e da calcificação in vitro de membranas de fibroina de seda para a aplicação como biomaterial. 2009. $72 \mathrm{f}$. Dissertação (mestrado) - Universidade Estadual de Campinas, Faculdade de Engenharia Quimica, Campinas, SP. 2009.

ZORTÉA, Areli D.'Agnoluzzo; FISCHER, Marta Luciane. Padrão de descarte de presas e avaliação da atividade antimicrobiana de constituintes da teia de Loxosceles intermedia Mello-Leitão, 1934 e Loxosceles laeta (Nicolet, 1849) (Araneae; Sicariidae). Revista Brasileira de Zoociências, v. 11, n. 1, 2009. 